\title{
School science
}

VoL. III]

JUNE, I903.

[No. 3

\section{PAST AND PRESENT THEORIES OF ELECTRICITY.}

\author{
BY A. P. CARMAN. \\ Professor of Physics, University of Illinois.
}

When the English court physician, William Gilhert, published, in 1600, his book on "Magnetic Bodies and the Lodestone," he included in it a chapter on the attraction of amber for light bodies. He writes: "Of this substance a few words must be said to show the nature of the attachment of bodies to it, and to point out the vast difference bctween this and the magnetic actions; for men still continue in ignorance and deem that inclination of bodies to amber to be an attraction and comparable to the magnetic coition." Gilbert was the first to break away from the scholastic methods of the middle ages. He says of the scholastic philosophy: "Such philosophy bears no fruit; for it rests simply on a few Greek or unusual terms-(used) just as our barbers toss a few Latin words in the hearing of the ignorant rabble in token of their learning and thus win reputation-(it) bears no fruit, bccause few of the philosophers themselves are investigators or have any first-hand acquaintance with things." Gilbert then narrates his experiments, showing that a great number of substances, as glass, sulphur, sealing wax, rock crystal and the precious stones, gain this property by friction. Such bodies he calls "electrics," and then he proceeds to seek the cause of this electrical attraction. We have thus here at the very beginning of electrical science three centuries ago the

*An address delivered before the Central Association of Science and Mathematics Teachers at Chicago, April 10, 1903 . 
question which we are still asking today, "what is electricity ?" and the search for the answer was thus early seen to demand "firsthand acquaintance with things." During these three hundred years our knowledge of electrical phenomena has grown far beyond any dream of Gilbert's generation, so that we now know that the attraction of amber is no isolated fact, and that the answer to the question "what is electricity?" would also tell us what light is, and perhaps what matter itsell is. It is the purpose of this paper to trace briefly the lines of the development of our conceptions of electrical phenomena, and to note more particularly a few of the leading results of the admirable rescarches of the last six or seven years, especially in reference to past theories.

A study of the many theories and conceptions of electricity that have been advanced in these three centuries shows that four general views scem to represent the course of historical growth of our ideas of electricity. These may be named, the effluvium view, snggested in its first form by Gilbert; the fluid view, connected with the names of Franklin and Symner; the ether view, with which we associate the names of Faraday, Maxwell and Hertz; and the atomic or corpuseular view, which has been developed in the very recent years, largely by Prof. J. J. Thomson, and his pupils of the Cavendish Laboratory of Cambridge University.

The first of these theories requires but a few words here. Gilbert ascribed the electrical attraction to an effluvium exhaled by the bodies, and thought of the bodies as surrounded by an electrical atmosphere. It was this electrical atmosphere which acted on the bodies attracted. The effluvium theory under different forms persisted for a century and a half. Our present interest in it is principally as the theory preceding the time of Franklin.

During the years between Gilbert and Franklin from 1600 to ahout 1750 , the scientific world was very busy experimenting with electricity. The division of bodies into electrical conductors and non-conductors had been discovered; the electric spark had been observed and felt; the fact of electrical repulsion as well as attraction had been noted; the two kinds of electrical states, vitreous and resinous, had thus been distinguished; and in 1745 the Dutch philosophers, Cunaeus and Mushenbrock, had discovered "the Leyden Phial," a discovery that produced the greatest sensation of the 
day. It was just after this that Benjamin Franklin began his electrical experiments, probably incited to them largely by the popular interest in the Leyden jar. Franklin was at that time fortyone years old, the leading citizen of Philadelphia, and brought to these experiments his best energies. He writes on March 28, 174\%, to Peter Collison, a member of the Royal Society of London, "For my own part, I never was before engaged in any study that so totally engrossed my attention and my time as this has lately done; for what with making experiments when $I$ can be alone, and repeating them to my friends and acquaintances, who from the novelty of the thing come continually in crowds to see them, I have during some months past had little leisure for anything else." Franklin's active experimental work continued for about ten years and is recorded in his "T.etters on Electricity," a classic work in electrical Jiterature, and scarcely less frscinating reading than his famous "Autobiography." It is not the place here to take up Franklin's electrical work in detail. He is distinguished in the history of electricity as being the first to present in an acceptable form a complete theory of electricity. Even to this day it is in many respects the most noteworthy of electrical theories. At a single stroke Franklin's theory made possible a clear description of phenomena which before had been vague and involved. Franklin's theory was the famous single fluid theory of electricity. $\mathrm{He}$ assumed electricity to be a subtle matter or fluid. "In common matter," he says, "there is generally as much of the electrical (matter) as it will contain within its substance." If more is added, the body is said to be electrified positively; and when part of the natural proportion of electrical fluid is taken out, the body is electrified negatively. He then completes the theory by assuming an attraction between the common and electrical matter, and a repulsion between two quantities of electrical matter. With this theory Franklin explained as well as we can today the facts of electrical attraction and repulsion, of electrification by influence or induction, and the charging and discharging of the Leyden jar. Franklin was not the first to advance the idea of a fluid theory, but Franklin's clean-cut and original methods of experiment and statement gave the theory a form which secured its general acceptance, ard hence the name Franklin's theory. And further, Franklin's 
form of the fluid theory was not the only form that found acceptance. Many of the greatest investigators in electricity have preferred to look on the electric fluid as a two-part fluid. Robert Symner, an English contemporary and acquaintance of Franklin, was probably the first to suggest such a theory. He writes in the Philosophical Transactions for 1759 (Vol. XI, abridged edition) : "When a body is said to be positively electrified, it is not simply that it is possessed of a larger share of electric matter than in the natural state; nor when it is said to be negatively electrified of a les: $\mathrm{s}$; but that, in the former case, it is possessed of a larger portion of one of these active powers, and in the latter of a larger portion of the others; while a body in its natural state remains unelectrified from an equal balance of these two powers within it." Hence followed the two fluid statement of the fluid conception of electricity, the language of which has been more generally used in electrical literature than any other. We shall see in the latter part of this paper that Franklin's original statement is, however, nearer the truth.

After Franklin came a period of measurement and mathematical statement. Conlomb, in 1785, proved that the force between two electrical charges decreases as the squares of the distonces between the charges increases; that is, that electrical forces fallow the same laws as Newton's law for gravitational forces. The mathematical methods of the astronomer thus became immediately available, and a mathematical theory of electrostatics was brilliantly developed by such great writers as Laplace, Biot and Poisson. In fact, by 1820 electrostatics, to quote Prof. Rowland, "was very far advanced even as compared with our modern times." This application of gravitational mathematics had, however, added to or emphasized in the accepted fluid theory one most important idea. The electrical forces were assumed to act directly across space, like gravitational forces; they were assumed to be forces acting directly a: a distance.

The next great name in the theory of electricity is that of Michael Fraday. Although born in humble surroundings and with none of the advantages of a university training, Faraday raised himself by his industry and genius to the highest rank in science. In 1820 he was a professor in the Royal Institution of 
London, the successor of the great chemist, Sir Humphrey Davy. In that year Hans Christian Oersted published his splendid discovery of the magnetic action of the electric current of Galvani and Volta. . This great discovery turned Faraday's mind to electrical experiments, but it was not until ten years later, in 1831, that Faraday's epoch-making "Experimental Researches" in electricity began to appear. The history of electricity from that time has the name of Faraday writ large on every page. He discorered electromagnetic induction and thus made possible the dynamo, the induction coil, and the alternating current transformer; he discovered the laws of electrolysis and laid the basis of the science of electrochemistry; he discovered the true action of insulators or dielectrics; while diamagnetism and the action of magnetic force on polarized light were first found by him. Great as Faraday's name is for these epoch-making discoveries, he is even more distinguished in science as the originator of a conception of the nature of electrical and magnetic forces, which has not only revolutionized the science of electricity and magnetism, but also the theory of light and radiant energy. Faraday had one of those rare independent minds which can free themselves from traditional opinions and can see things as they are. He was, as Hertz says, "a man who looked at phenomena with an open mind and without preconceived opinions, who started from what he saw, not from what he had heard, learned or read." And what did Faraday see? He saw two bodies drawn toward each other. What was the cause? Others had explained the attraction as due to something called electricity cu the bodies. But electricity was something he could not perceive, si, instead of trying to explain something of which the very existence was hypothetical, he turned to investigate that which he could get at, that is the force between the bodies. Now the only way that Faraday could conceive of a force was as a push or a pull. To his mind the conception of a hypothetical agent acting at a distance aftorded no explanation. So he turned to the space betwcen the bodies to find the push or pulb. Taking a little test body he could map out the direction of the force at each point in space, and thus could draw the lines of the force or "electric curves", as he at first called them. Further he proved that these electric curves or lines always joined to bodies which were being attracted to each other. 
So he was led to his conception of lines of force. These lines of force became for him physical realities with just as actual an existence as elastic threads fastened on the two bodies and drawing them together. But how explain the existence of these lines? The answer was that they were lines of tension in a fluid medium, an ether. The idea of an ether was not new. Recently, Young and Fresnel had explained the most complicated phenomena of light by such an ether. Thus, Faraday satisfied his own mind and banished actions at a distance, substituting stresses and motions in the ether. But the point of view was so new and strange that it was long before others could follow. Undoubtedly Faraday's peculiar methods of statement had much to do with this. For Faraday was not a professed mathematician, although as Helmholtz says, "with quite a wonderful sagacity and intellectual precision Faraday performed in his brain the work of a great mathematician without using a single mathematical formula. He saw with his mind's eye that magnetized and diclectric bodies ought to have a tendency to contract in the direction of the lines of force and to dilate in all directions perpendicular to the former; that by these systems of tensions and pressures in the space which surrounds electrificd bodies, magnets or wires conducting electric currents, all the phenomena of electro-static, magnetic electro-magnetic attraction, repulsion and induction could be explained without recurring at all to forcess acting at a distance." As we follow the growth of these ideas in those wonderful "Experimental Researches" our admiration for the mind that could originate and formulate them is unmeasured.

But it is largely due to James Clerk Maxwell that the conceptions of Faraday were given that form and definiteness without which they would have failed to have affected science. Maxwell, unlike Faraday, was a trained mathematician. He had been ax honor and prizeman in the most famous mathematical contest of the English universities. In electricity he had had no training except a close and profound study of Faraday's published work. He speaks, in his first memoir on this subject, of electricity as "a science in which I have hardly made a single experiment." He tells us in the introduction to his "Elcctricity and Magnetism," that his purpose was to translate Faraday's ideas into mathematical form, but he did more than translate, for Maxwell was one of the 
rarest of creative geniuses Hertz says of the great paper which Maxwcll read before the Royal Society in 1864: "It is impossible to study this wonderful theory without feeling as if the mathematical equations had an independent life and jntelligence of their own; as if they were wiser than ourselves; jndeed, wiser than their discoverer, as if they gave forth more than he put in them." The Faraday theory grew in Maxwell's hands, so that not only were the facts of electricity and magnetism given a formal dynamical explanation as stresses and motions in the ether, but it was shown that light was a periodic electro-magnetic action in this same ether. Maxwell's theory gained acceptance very slowly. At the time of Maxwell's death in 1879, "His supporters," says Prof. Glazebrook, "were limited to some few English-speaking pupils, young and enthusiastic, who were convinced, it may be in no small measure, by the affection and reverence with which they regarded their master." On the continent of Europe, the thcory made almost no headway. Professor Boltzmann says that up to $188 \%$, only two professors in the German-speaking universities mentioned Mrxwell's theory in their lectures, Helmboltz in Berlin, and Stefan in Vienna, and they did not accept it. The theory was so different from all previous ideas that to most it seemed ingenious speculation rather than serious science. But in $188 \%$ and 1888 there came $x$ series of beautiful experiments which so completely verified Maxwell's findamental conceptions that the whole world was almost instantly converted to the essential truth of the ideas of Faraday and Maxwell. These experiments were the electric wave experiments of Heinrich Hertz. What Hertz did was to produce periodic electric disturbances or waves and to show that these electric waves were propagated with a finite velocity, the velocity of light, and further that these electric waves were identical with the waves called light in all except wave lengths. The existence of the electro-magnetic ether was thus proven, and also the transmission of electric and magnetic forces through this ether.

After the striking confirmation of Maxwell's equations by Hertz's electric waves there came a period when many thought that there was no electricity, that what we had called electricity was simply a positive or negative displacement of the ether, showing itself at the boundary surfaces of conductors and insulators. Thus, 
Dr. Oliver Lodge, in the introduction to his book on "Modern Views of Electricity," in 1889 says: "Few things in physical science appear to me more certain than what has so long been called electricity is a form or rather mode of manifestation of the ether. Such words as 'electrification' and 'electric' may remain; 'electricity' may gradually have to go. It can be noticed that whereas in the earlier part of the book the word 'electricity' occurs frequently and the word 'ether' scldom, in the latter portion this order of frequency is inverted." Still more emphatically wrote Prof. Rowland, in 1895. He wrote: "It is not uncommon for electricians to be asked whether modern science has yet determined the nature of electricity, and often find difficulty in answering the question. When the question comes from a person of small knowleilge which we know to be of a vague and general character, we naturally answer it in an equally vague and general manner; but when it comes from a student of science anxious and able to bear the truth, we now answer with certainty that electricity no longer exists." These quotations indicate the ideas held by most of the ablest students ten years ago.

We now turn to the more recent theory of the nature of electricity, and it will be seen it involves also new views of the atom and of the nature of matter. We will first state briefly the theory and note a few of the reasons and results of it later. The theory may be summarized as follows: Every atom of ordinary matter has connected with it one or more smaller particles, called by Prof. J. J. Thomson corpuscles. These corpuscles are small, both in mass and size, as compared with the smallest atom. Compared with the hydrogen atom, the mass of a corpuscle is only as one to one thousand. Further, all corpuscles are of the same mass, whatever the kind of atom with which they are associated; that is, the corpuscles associated with oxygen are of the same mass and size as those with hydrogen, uranium or any other kind of matter. Each corpuscle is the bearer or carrier of a definite charge of resinous or negative electricity. As long as the corpuscle is joined to the atom, the atom is in a neutral electric state, but when the corpuscle is separated or dissociated from the atom, the atom is left charged positively, while the dissociated corpuscle is negatively 
charged. That is, calling the two parts of the atom, ions, an atom is composed of two ions, a positive ion of a size and mass which depends on the kind of matter, and a negative ion of an invariable mass, about one thousandth the mass of the hydrogen atom. Then to charge a body positively, we remove the corpuscles or negative ions; to charge the body negatively, we add a surplus of corpuscles to it. A further property of the corpuscles is their penetrating power and great mobility. They can move through a metal and can when free be given velocities second only to that of light. An electric current is carried by these negatively charged corpuscles; that is, an electric current is simply a stream of these corpuscles with their negative charges. We have called the corpuscles the carriers of the charge, but some physicists think the corpuscles may be themselves the negative electricity. In conformity with that idea, they have been called electrons, a word suggested first by Dr. Johnstone Stoney, for the charge carried by an ion in electrolysis. Lord Kelvin uses the word electron for the same purpose. Prof, J. J. Thomson in his latest paper (March, 1903) returns to the term negative ion.

It scems hardly necessary to suggest that we are here back to the one fluid theory of Franklin, only the fluid has become atomic and its sign is changed. 'Two questions naturally come immediately to our lips: First, what are the reasons for advancing and holding this corpuscular or atomic theory? Next, how does it harmonize with the ether theory of Faraday and Maxwell?

To review the experiments and reasons which have led to this surprising and radical return to old ideas would be out of place in a paper of the length and character of this. It would involve an aistract of a literature which, while only six or seven years old, aiready numbers hundreds of papers and references as well as the explanation of new and involved methods of investigation. But a short statement of the range and principles of the researches may be made.

In the first place, it may be noted that these new concepts have come largely from a study of the passage of electricity through gases, and also from the application of the newer ideas of electrochemistry to gases. The line of research started with attempts to explain the discharge phenomena in the high vacuum tubes or 
Crookes tubes. As is well known, in such tubes the negative electrode or cathode has streaming from it the peculiar cathode rays. Thomson found that these cathode rays were streams of extremely fine particles, the corpuscles of this new atomic theory. But the theory does not rest on a study of cathode rays alone. In 1896 Becquerel announced the important discovery of a new kind of: radiation having many of the properties of the Roentgen rays. These rays are emitted by uranium, thorium, radium and probably by numbers of other substances. It has been shown that these radio-active substances are emitting these corpuscles. Further, Thomson and others have shown that metals illuminated by Roentgen rays or by ultra-violet light, and also incandescent metals give off the same corpuscles. All these cases, investigated by many persons with independent methods, have yielded the same results, so that the theory although new, aiready stands on a firm basis of experiment. In addition the atomic nature of clectricity is not a new conception, nor one that has ceased at any time to be held by many thoughtful physicists. In the last volume of Helmholtz's papers in a lecture on Faraday's concepts, we find Frelmholtz saying: "Now the most startling result of Faraday's law (of electrolysis) is perhaps this. If we accept the hypothesis that the elementary substances are composed of atoms, we cannot avoid concluding that electricity also, positive as well as negative, is divided into definite elementary portions, which behave like atoms of electricity." Helmholtz here refers to the quantity of electricity carried by an ion in electrolysis. The hydrogen ion for instance always carries $8 \times 10^{-20}$ coulombs of electricity in any solution, and all other monad ions carry the same amount. Hence this quantity has been regarded as the natural unit of electricity, and called an "electron." It seems to be the smallest quantity of electricity that can exist in nature, and the laws of electrolysis indicate that all possible electric quantities are multiples of the electron. It is this same unit, the electron, that Thomson finds on the corpuscles. Possibly the corpuscle is the electron. If so, we are back to a material theory of electricity.

Certainly the new theory brings us much nearer to the nature of matter than anything ever reached before, and already scien- 
tific literature is full of fascinating speculations on the part played by electrons in the activities of matter.

How does the new theory harmonize with the older theories? As already pointed out, it agrees with the single fluid theory, so that in the future we need not fight shy of the word electricity. With the ether theory, there are no doubt many difficulties to explain. The essential feature of the Faraday-Maxwell-Hertz conception of the ether has becn proved beyond question. This essential is that there is an ether by which electric and magnetic forces are transmitted, so that the conception of force acting at a distance is banished; and, further, that this electro-magnetic ether is the same as the luminous ether, so that electric waves and light waves are the same, differing only as red light differs from blue light, in wave length. It was never an essential of the ether theory that the electric charge should be an cther phenomenon. In fact that was one feature of Maxwell's theory that was always vague. T'hus Helmholtz wrote in 1881: "I confess I should really be at. a loss to explain without the use of mathematical formulae what he (Maxwell) considers as a quantity of electricity. *** It is not at all necessary to accept any definite opinion about the ultimate nature of the agent which we call electricity. Faraday himself avoided as much as possible giving any affirmative assertion regarding this problem, although he did not conceal his disinclination to believe in the existence of. two opposite electric fluids." Perhaps we cannot better state the condition of the barmony of these theories than by a quotation from Prof. G. H. Bryan. He says: "The discovery of rays capable of discharging electrified bodies in air has not only shown the fallacy of our preconceived dogmatic netions as to the division of substances into conductors and dielectrics, but has taught us that the properties of the ether are not so simple as we had anticipated. We can only wonder whether Maxwell would have been able to develop his electro-magnetic and electro-optic theories had the complications arising from the Becqucrel and other rays been before him; and the want now makes itself felt of a second Maxwell, who shall co-ordinate the newly-accumulated mass of experimental facts into the form of a connected mathematical theory." 